\title{
Redução de Gordura e Açúcar em Biscoitos tipo Cookie
}

\author{
Rosine Pereira Amstalden*, Caroline Joy Steel
}

\begin{abstract}
Resumo
A indústria de alimentos tem, cada vez mais, buscado alternativas para redução de açúcar e gordura, já que a população se preocupa com o consumo excessivo desses ingredientes. Sendo assim, o presente trabalho tem como objetivo, a partir de uma formulação-base de cookie com gotas de chocolate, estudar as alterações físico-químicas provocadas pela redução de açúcar e gordura. Além disso, a gordura foi substituída por três ingredientes, e verificouse o desempenho de cada substituto nos cookies. Os biscoitos com os melhores resultados foram escolhidos para aplicação de uma análise sensorial, visando determinar a aceitação e intenção de compra dos consumidores.
\end{abstract}

Palavras-chave: biscoitos, redução açúcar e gordura, substituintes de gordura.

\section{Introdução}

Açúcar e gordura, quando consumidos em excesso, estão associados a algumas doenças, como diabetes e obesidade ${ }^{1}$. Porém, para a indústria de alimentos, os dois ingredientes são importantes, conferindo sabor e textura característicos. No caso dos biscoitos tipo cookie, é o alto teor de gordura que caracteriza o sabor e a textura, e o açúcar confere volume e doçura, o que dificulta a redução ou substituição desses ingredientes ${ }^{2}$.

Os substitutos de gordura mais utilizados em produtos de panificação têm carboidratos como base ${ }^{3} \mathrm{e}$, por isso, foram escolhidos maltodextrina, amido modificado e polidextrose como substituintes.

O objetivo do trabalho foi avaliar as possíveis mudanças causadas pela redução de $20 \%$ de açúcar, e da substituição de $25 \%$ e $50 \%$ de gordura. A partir de análises físico-químicas, as formulações com melhores resultados foram selecionadas para avaliação sensorial dos consumidores, determinando a aceitabilidade e intenção de compra.

\section{Resultados e Discussão}

Inicialmente, foram realizadas análises de caracterização das matérias-primas, ou seja, da farinha de trigo e dos substituintes de gordura. Todos passaram por análise de cor instrumental e composição centensimal, além de farinografia, alveografia, Falling Number e teores e índices de glúten para a farinha. Os resultados obtidos foram coerentes com os esperados, estando de acordo com o encontrado na literatura.

Então, as formulações com redução de açúcar (20\%) e gordura (25\% e $50 \%$ ) e substituição da gordura foram elaboradas, e realizaram-se análises de qualidade tecnológica: atividade de água, umidade, textura e dimensões.

Determinou-se como sendo o controle para aplicação da análise sensorial o biscoito com $20 \%$ de redução de açúcar, já que os resultados foram semelhantes ao da formulação base, a qual não possuía redução de açúcar ou gordura. Além disso, levou-se em consideração o fato de que todas as outras formulações, em que a gordura seria reduzida e substituída, também teriam essa mesma redução de açúcar, sendo mais coerente para comparação.

Cada substituto foi adicionado de $25 \%$ e $50 \%$, e os resultados dos testes de qualidade auxiliaram na escolha de qual redução seria aplicada na sensorial. As formulações com resultados mais próximos ao da formulação controle foram levadas para a análise sensorial.

A partir dos resultados obtidos pela análise sensorial, foi possível realizar uma análise estatística dos dados através da variância (ANOVA) e comparação das médias de pares de amostras pelo teste de Tukey. Observou-se uma diferença significativa entre todos os atributos avaliados (aparência, sabor, textura e impressão global), com exceção do aroma. A formulação com melhores resultados foi a controle, seguida da com substituição de $25 \%$ de maltodextrina, polidextrose e, por fim, amido modificado. A intenção de compra global está descrita na Figura 1.
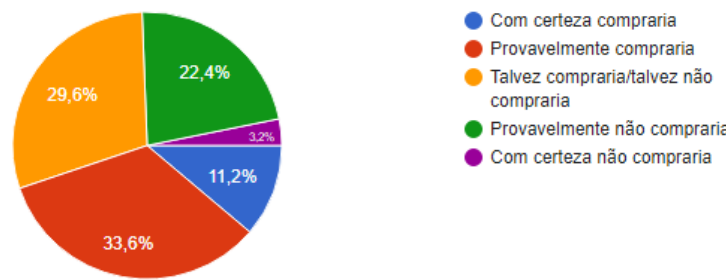

Figura 1. Intenção de compra

\section{Conclusões}

A aceitação dos biscoitos com redução e substituição de gordura foi dificultada, pois tal ingrediente é responsável pela textura. Porém, é possível notar que, apesar da diferença significativa entre as amostras, a maior porcentagem foi a de $33,6 \%$, que corresponde à provavelmente compraria. Então, os biscoitos com substitutos não foram rejeitados, com potencial para uma inserção no mercado.

\section{Agradecimentos}

Ao PIBIC e ao CNPq, pela concessão da bolsa de iniciação científica.

${ }^{1}$ KEAST, R. S. J. Effects of sugar and fat consumption on sweet and fat taste Current Opinion in Behavioral Sciences. v.9, p. 55-60, 2016.

${ }^{2}$ ZOULIAS, E. I., OREOPOULOU V. \& KOUNALAKI, E. Effect of fat and sugar replacement on cookie properties. Journal of the Science and Food and Agriculture. 2002

${ }^{3}$ ADITIVOS \& INGREDIENTES. Substitutos de Gordura. Disponível em: $<$ http://aditivosingredientes.com.br/upload_arquivos/201601/201601099491000 1454074039.pdf>. Acesso em 05/04/2018. 